UCRL-JC-125218

PREPRINT

\title{
Application of Soft X-ray Lasers for Probing High Density Plasmas
}

L. B. Da Silva, T. W. Barbee, Jr., R. Cauble, P. Celliers, C. D. Decker, D. H. Kalantar, M. H. Key, R. A. London, J. C. Moreno, J. E. Trebes, A. S. Wan, F. Weber

This paper was prepared for submittal to the

5th International Conference on X-ray Lasers

Lund, Sweden

June 10-14, 1996

August 30, 1996

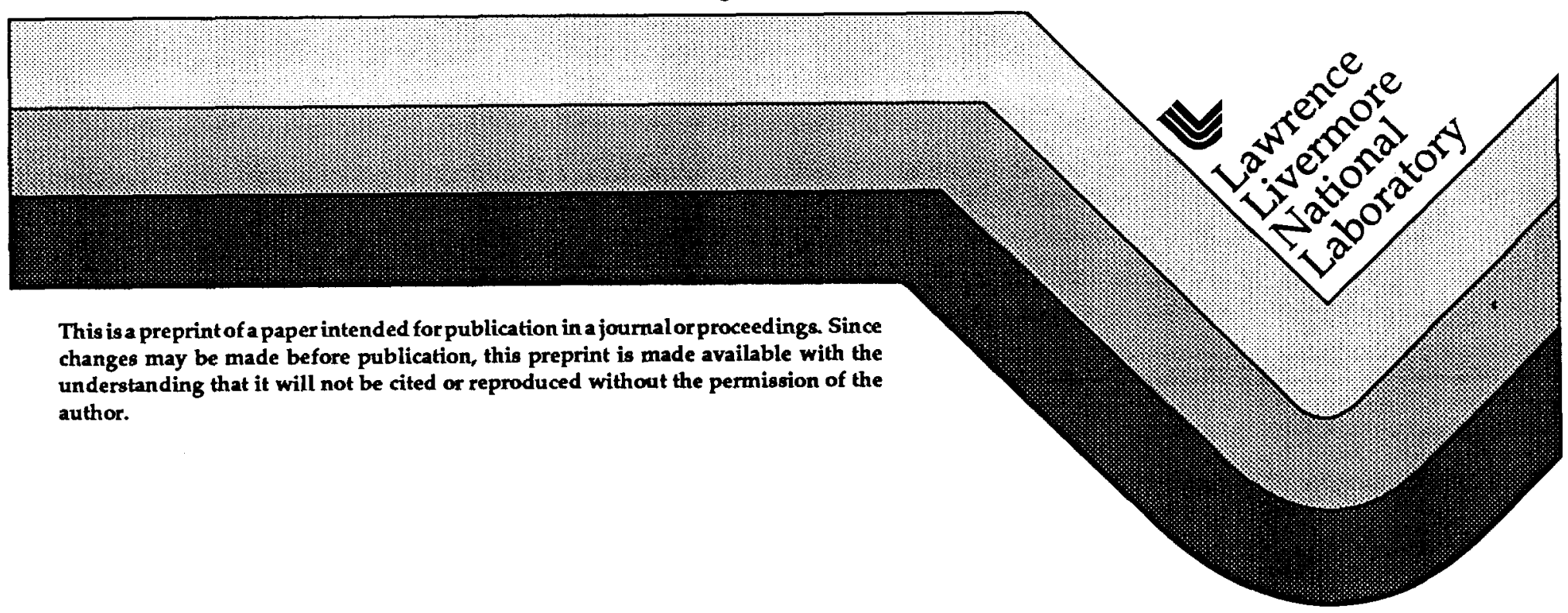




\section{DISCLAIMER}

This document was prepared as an account of work sponsored by an agency of the United States Government. Neither the United States Government nor the University of California nor any of their employees, makes any warranty, express or implied, or assumes any legal liability or responsibility for the accuracy, completeness, or usefulness of any information, apparatus, product, or process disclosed, or represents that its use would not infringe privately owned rights. Reference herein to any specific commercial product, process, or service by trade name, trademark, manufacturer, or otherwise, does not necessarily constitute or imply its endorsement, recommendation, or favoring by the United States Government or the University of California. The views and opinions of authors expressed herein do not necessarily state or reflect those of the United States Government or the University of California, and shall not be used for advertising or product endorsement purposes.

This report has been reproduced directly from the best available copy.

Available to DOE and DOE contractors from the Office of Scientific and Technical Information

P.O. Box 62, Oak Ridge, TN 37831

Prices available from (615) 576-8401, FTS 626-8401

Available to the public from the

National Technical Information Service

U.S. Department of Commerce

5285 Port Royal Rd.,

Springfield, VA 22161 


\title{
Application of Soft X-ray Lasers for Probing High Density Plasmas
}

\author{
L.B. Da Silva, T.W. Barbee, Jr., R. Cauble, P. Celliers, C.D. Decker, D.H. Kalantar, \\ M.H. Key, R.A. London, J.C. Moreno, J.E. Trebes, A.S. Wan and F. Weber. \\ Lawrence Livermore National Laboratory, P.O. Box 808, L-399, Livermore, California, U.S.A. 94550
}

\begin{abstract}
The reliability and characteristics of collisionally pumped soft $\mathrm{x}$-ray lasers make them ideal for a wide variety of plasma diagnostics. These systems now operate over a wavelength range extending from 35 to $400 \AA$ and have output energies as high as $10 \mathrm{~mJ}$ in 150 ps pulses. The beam divergence of these lasers is less than 15 mrad and they have a typical linewidth of $\Delta \lambda / \lambda \sim 10^{-4}$ making them the brightest xuv sources available. In this paper we will describe the use of $x$-ray lasers to probe high density plasmas using a variety of diagnostic techniques. Using an $\mathrm{x}$-ray laser and a multilayer mirror imaging system we have studied hydrodynamic imprinting of laser speckle pattern on directly driven thin foils with $1-2 \mu \mathrm{m}$ spatial resolution.Taking advantage of recently developed multilayer beamsplitters we have constructed and used a Mach-Zehnder interferometer operating at $155 \AA$ to probe $1-3 \mathrm{~mm}$ size laser produced plasmas with peak electron densities of $4 \times 10^{21} \mathrm{~cm}^{-3}$. A comparison of our results with computer simulations will be presented.
\end{abstract}

\section{Introduction}

Advances in optical laser technology have now made it possible to generate and study a wide range of laboratory plasmas with densities and scalelengths exceeding previous systems. Large laser systems such as the NOVA laser at Lawrence Livermore National Laboratory can easily produce several millimeter scale plasmas with electron densities exceeding $10^{21} \mathrm{~cm}^{-3}$. At these densities absorption and refraction severely limit the use of conventional optical techniques. This has motivated our recent work to use soft $x$-ray lasers (XRL) for probing these large laser produced plasmas. Section II describes the properties of existing collisionally pumped soft $x$-ray lasers which make them ideal for probing applications. These xuv sources are now routine and operate over a wide wavelength range well suited to multilayer mirror optics. Section III illustrates the use of $x$-ray lasers to study beam imprinting in laser driven foils. The high brightness of the $x$-ray laser makes it possible to achieve foil thickness sensitivities of approximately $100 \AA$. Section IV describes the development of interferometry at $155 \AA$ and its use to probe large plasmas relevant to Inertial Confinement Fusion (ICF) and Astrophysics. Finally $\mathrm{Sec}$. V will describe our plans to further develop these diagnostic tools and study mechanisms such as relativistic channeling and the dynamics of colliding plasmas.

\section{Properties and advantages of x-ray lasers}

As is evident in these proceedings soft $\mathrm{x}$-ray lasers have now been demonstrated by researchers worldwide and can operate over the range $35-400 \AA$. Historically; these systems have utilized high power optical lasers to produce a hot and uniform plasma suitable for laser amplification and propagation. More recently using multi pump pulse techniques the efficiency and range of collisionally pumped systems has been increased ${ }^{1}$. Saturated output has been reported in selenium $^{2}$, germanium ${ }^{3}$ and yttrium ${ }^{4}$ using optical pumping and in argon using capillary discharges 5,6 . The high brightness and comparatively routine operation of existing soft $x$-ray lasers has opened up the possibility of using these systems for a variety of applications. The use of Ni-like tantalum $x$-ray laser for biological imaging has already been demonstrated ${ }^{7}$ and will ultimately allow us to study biological specimens in a natural environment with resolutions far exceeding that possible with optical techniques. The high brightness of saturated $\mathrm{x}$-ray lasers also makes them an ideal tool for probing high density and large plasmas relevant to astrophysics and ICF. In addition, the wide range of available $x$-ray laser wavelengths (shown in Figure 1) now make it possible to take advantage of absorption edges to enhance contrast. In this paper we will focus on the use of soft $x$-ray lasers to study laser produced plasmas. 


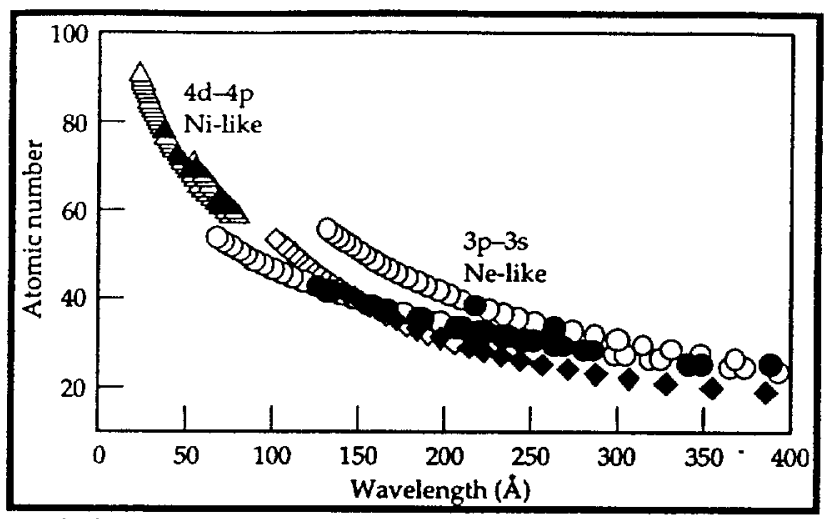

Figure 1. Measured (filled symbols) and calculated (open symbols) wavelengths as a function of atomic number for primary neon-like $(3 p-3 s)$ and nickel-like $(4 d-4 p)$ collisionally pumped $x$-ray lasers.

There are two main effects which ultimately limit the plasma conditions which can be probed with any laser source. The first is absorption and it limits the density of the plasma, the second is refraction which limits the density gradients. In a plasma with electron density $n_{e}$, the index of refraction, $n_{r e f}$ is related to the critical electron density, $n_{c r}=1.1 \times 10^{21} \lambda^{-2}\left[\mathrm{~cm}^{-3}\right](\lambda$ in $\mu \mathrm{m})$, by $\mathrm{n}_{\text {ref }}=\sqrt{1-\frac{n_{c}}{n_{c r}}}$. In an interferometer the number of fringe shifts, $N_{\text {Fringe }}$, is then given by

$N_{\text {Fringe }}=\frac{\delta \phi}{2 \pi}=\frac{1}{\lambda} \int_{0}^{L}\left(1-\mathrm{n}_{\text {ref }}\right) d L \approx \frac{n_{e}}{2 n_{c r}} \frac{L}{\lambda}=4.54 \times 10^{-22} n_{e} L \lambda$

where the integral is along ray trajectories through the plasma, $d L$ is the differential path length, $L$ is the plasma length and we assume refraction effects are negligible. Experimentally the maximum number of fringe shifts measurable is usually constrained by detector resolution and is rarely greater than $\sim 50$. This imposes a constraint on the product $n_{e} L$ for a given wavelength. However, absorption is a more significant constraint on the accessible plasma density and size. We can estimate this parameter space by considering only free-free absorption which in the soft $\mathrm{x}$ ray wavelengths dominates since the plasmas of interest are sufficiently ionized to eliminate any bound-free contribution and resonant line absorption is unlikely. Under these conditions the absorption coefficient, $\alpha$, is approximately given by ${ }^{8}$

$\alpha=2.44 \times 10^{-37} \frac{\left\langle Z^{2}\right\rangle n_{\mathrm{e}} n_{\mathrm{i}}}{\sqrt{\mathrm{T}_{\mathrm{e}}(h v)^{3}}}\left[1-\exp \left(\frac{-h v}{\mathrm{~T}_{\mathrm{e}}}\right)\right] \mathrm{cm}^{-1}$

where the electron temperature, $T_{\mathrm{e}}$, and photon energy, $h v$, are in $\mathrm{eV}$ and $n_{\mathrm{e}}$ and ion density $n_{\mathrm{i}}$ are in $\mathrm{cm}^{-3}$. The strong scaling with photon energy shows the advantage of probing with soft $\mathrm{x}-$ ray sources. For most high temperature plasmas of interest, the level of ionization is sufficient to eliminate any bound-free absorption in the soft x-ray region. Resonant line absorption is possible but very unlikely given the narrow bandwidth of the $\mathrm{x}$-ray laser $\sim 10 \mathrm{~m} \AA$. Therefore, if we consider only free-free absorption in a plasma with $1 \mathrm{keV}$ temperature and average ionization 30 (mid-Z plasma) we obtain from Eq. $1, \alpha \approx 2.6 \times 10^{-43} n_{e}^{2}$ for $\lambda=155 \AA$. If we allow for one optical depth (i.e. $\alpha L=1$ ) of absorption we obtain $n_{e}^{2} L=3.8 \times 10^{42}$. In Figure 2 we compare the electron density and plasma dimension accessible with a soft $\mathrm{x}$-ray laser source (155 $\AA$ ) and an optical laser source $(2500 \AA)$. The strong wavelength scaling $\left(\propto \lambda^{2}\right)$ makes it a clear advantage to probing with shorter wavelengths. The possible parameter space with a $155 \AA$ probe easily covers the plasmas normally produced in the laboratory. 


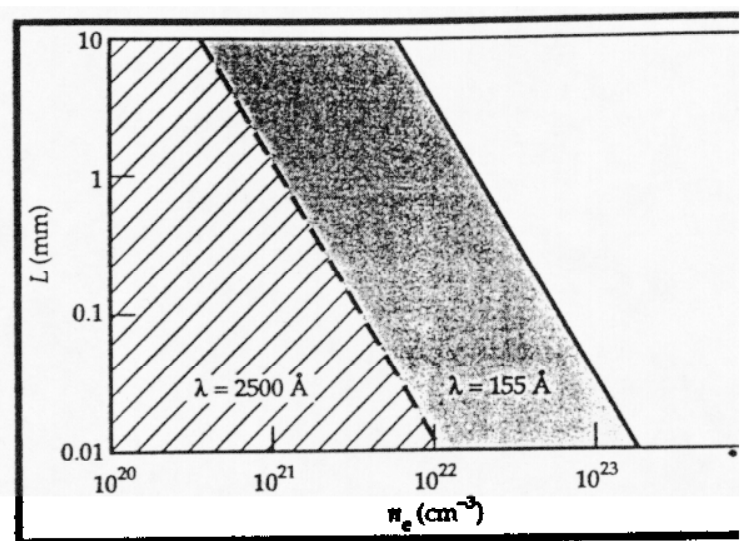

Figure 2. Parameter space accessible for plasma probing using an optical laser ( (155 A). Only free-free absorption is considered.
A) and a soft $x$-ray laser

A second effect which limits optical probing is beam refraction. Refraction of the probe beam is sensitive to electron density gradients and ultimately affects spatial resolution and data interpretation ${ }^{10}$. At $155 \AA$ critical density is $4.6 \times 10^{24} \mathrm{~cm}^{-3}$ which is well above most plasmas of interest. For a simple plasma with a linear density gradient $n_{e}=n_{o}\left(1-\left(y / y_{o}\right)\right)$, the deflection angle, $\theta$, scales as $\theta \propto \lambda^{2} L / y_{o}$. This strong scaling again makes it advantageous to use a short wavelength probe. In Figure 3 we compare the deflection angle after propagating through a $3 \mathrm{~mm}$ plasma for an optical $(2650 \AA)$ and xuv $(155 \AA)$ probe source. At a fundamental level large deflection angles imply significant spatial blurring and reduced spatial resolution. For example, a 10 mrad deflection angle leads to $10 \mu \mathrm{m}$ translation over a $1 \mathrm{~mm}$ long plasma. In addition, since probe rays will propagate through a range of electron densities interpretation of the results will be more difficult.

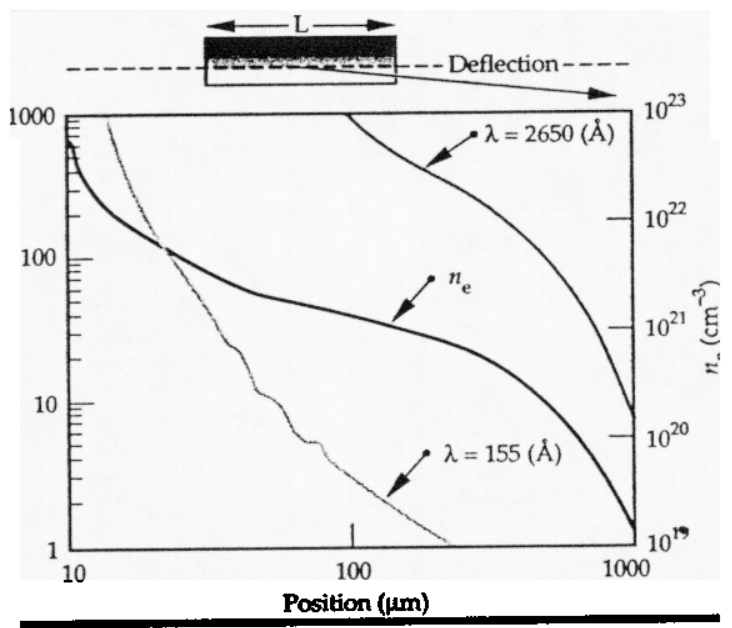

Figure 3. Calculated des and deflection for an optical and an $x$-ray laser probe aversing $3 \mathrm{~mm}$ of plasma produced by driving a $50-\mu \mathrm{m}$ thick $\mathrm{CH}$ target with a 1-ns square $0.53 \mu \mathrm{m}$ laser pulse at $2.0 \times 10^{13} \mathrm{~W} / \mathrm{cm}^{2}$.

The strong wavelength scaling of absorption and refraction $\left(\propto \lambda^{2}\right)$ help to counter the loss in sensitivity due to the linear scaling of fringe shift with probe wavelength. It is this difference in scaling that makes the xuv an attractive area to operate in. We mitigate the adverse effects without a significant loss of sensitivity. To date all our experiments for probing plasmas have utilized the yttrium $x$-ray laser. This neon-like collisionally pumped $x$-ray laser is well suited to this application by virtue of its high output power (Figure 4) and monochromatic output (i.e. dominated by a single line at $155 \AA)^{4}$. The wavelength is also well suited to existing multilayer mirror technology which have demonstrated reflectivities of $\sim 60 \%$. 


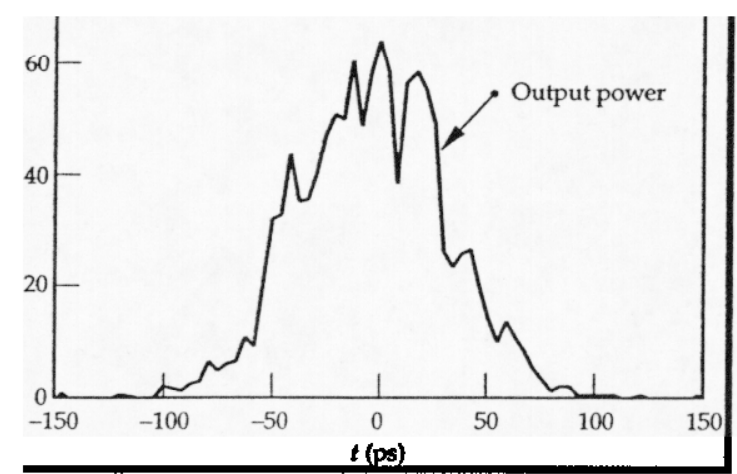

Figure 4. $\mathbf{N}$ red output power of 3-cm-long yttrium exploding foil $\mathrm{x}$-ray laser.

\section{Plasma imaging using soft $x$-ray lasers}

Plasma imaging with an $\mathrm{x}$-ray laser has been previously reported ${ }^{11}$ and demonstrated the potential of high resolution imaging with simple spherical multilayer mirrors. Recently we have extended this work to study laser imprinting in thin planar foils 12,13. In studying this effect it is important to maximize the experimental sensitivity to target modulations so that measurements can be made early in the pulse to reduce Rayleigh-Taylor growth. It is easy to show that the sensitivity is maximized when you use a target with a large optical depth ${ }^{13}$ which then requires the use of a bright probe. The experimental setup we used for these experiments is shown in Figure 5.

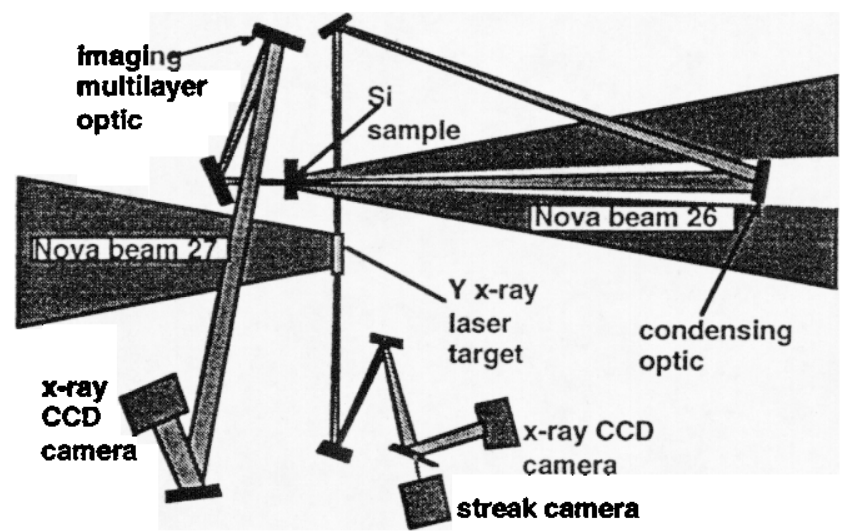

Figure 5 Experimental setup used to study laser imprinting using soft $x$-ray imaging.

The $x$-ray laser was produced by irradiating an exploding foil $3 \mathrm{~cm}$ long yttrium target with one beam from Nova $\left(\lambda_{\text {laser }}=0.53 \mu \mathrm{m}, 600 \mathrm{ps}\right.$ square) at an intensity of $1.5 \times 10^{14} \mathrm{~W} / \mathrm{cm}^{2}$. The $\mathrm{x}-$ ray laser has an output energy of $5 \pm 2 \mathrm{~mJ}$, a divergence of approximately $10 \mathrm{mrad}$ (FWHM) and an output pulse width of 80 ps. The x-ray laser beam is relayed by two Mo/Si multilayer mirrors; a flat mirror and a spherical multilayer mirror $(100 \mathrm{~cm}$ radius of curvature) which images a plane $2.2 \mathrm{~cm}$ from the end of the $\mathrm{x}$-ray laser amplifier onto the secondary silicon foil target which is to be driven. The driven foil is then imaged off a flat mirror with a spherical mirror $(50 \mathrm{~cm}$ radius of curvature) onto a backside illuminated $\mathrm{CCD}$ detector. An additional flat mirror was used after the imaging optic to further reduce the bandpass of the system. A $1000 \AA$ aluminum filter was placed in front of the CCD to eliminate optical light. The CCD was a back illuminated TEK1024B with 1024 by $102424 \mu \mathrm{m}$ pixels and a measured quantum efficiency of $40 \pm 10 \%$ at $155 \AA$. All multilayer mirrors consisted of 15 layer pairs of $\mathrm{Mo} / \mathrm{Si}$ and have a measured reflectivity of $60 \pm 5 \%$ at normal incidence. The effective bandpass of the multilayer mirror and filter combination is $8 \AA$ centered at $155 \AA$. The spatial resolution of this imaging system has been measured to be $\sim 1 \mu \mathrm{m}$ and is limited by the CCD detector pixel size of $24 \mu \mathrm{m}$ and spherical aberrations in the imaging system. In this experiment $3-4 \mu \mathrm{m}$ Si foils are irradiated at $3 \times 10^{12}$ $\mathrm{W} / \mathrm{cm}^{2}$ with a $0.5 \mathrm{~ns}$ square, $0.35 \mu \mathrm{m}$ wavelength beam from the NOVA laser. In Figure 6 we show the recorded image for three different irradiation conditions. Figure 6A was taken $260 \mathrm{ps}$ 
after start of the laser pulse to coincide with the breakout of the shock at the rear surface while Figure 6C was taken at 400 ps to allow for Rayleigh-Taylor growth. Figure 6A was obtained with a laser beam with no bandwidth whereas $6 \mathrm{~B}$ and $6 \mathrm{C}$ used a cross phase modulated beam with bandwidth of $1.4 \AA(0.33 \mathrm{THz})$. The measured RMS optical modulations for images in Figure $6 \mathrm{~A}, \mathrm{~B}, \mathrm{C}$ are $0.37,0.22$, and 0.58 respectively. The benefits of SSD and increased bandwidth are evident in the reduction in optical depth modulations. More details of this work and a comparison to model predictions can be found in a paper by Kalantar et al. 12 .

\section{$0.37 \mathrm{rms}$}

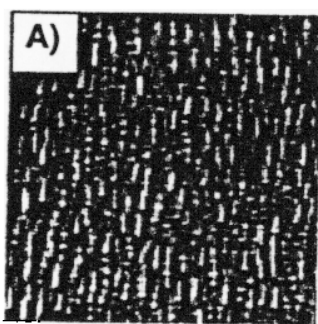

0.22 rms

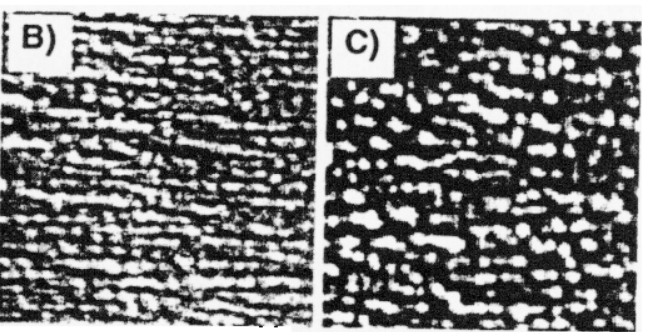

Figure 6. Images obtained of laser irradiated thin silicon foils. Image A) and B) were obtained 260 ps while image C) was $\mathbf{4 0 0}$ ps after the start of the drive. Image A) used a laser beam with no bandwidth. Image B) and C) used a laser beam with $1.4 \AA$ bandwidth. The measured RMS optical depth modulations of these images is shown.

\section{Electron density measurements using soft $x$-ray interfereometry}

In the study of laser produced plasmas optical interferometry has played a key role in the accurate measurements of electron density profiles for a variety of target conditions. Profile steepening due to radiation pressure was first quantified by Attwood et al. ${ }^{14}$ using a short pulse $2650 \AA$ optical interferometer. It has been used to measure electron density profiles in exploding foils under conditions relevant to $x$-ray 'lasers 15,16 . The filamentation instability in laser produced plasmas was investigated by Young et al.17,18 also using optical interferometry. In all these cases, however, the size of the plasma and the peak electron density accessible were severely restricted by absorption and refraction. For these reasons there has existed a need to develop interferometry techniques at soft $x$-ray wavelengths where absorption and refraction effects can be mitigated. We have combined a soft $x$-ray laser operating at $155 \AA$ and a multilayer-optic-based interferometer to probe a $\mathrm{mm}$ size $\mathrm{CH}$ plasma.

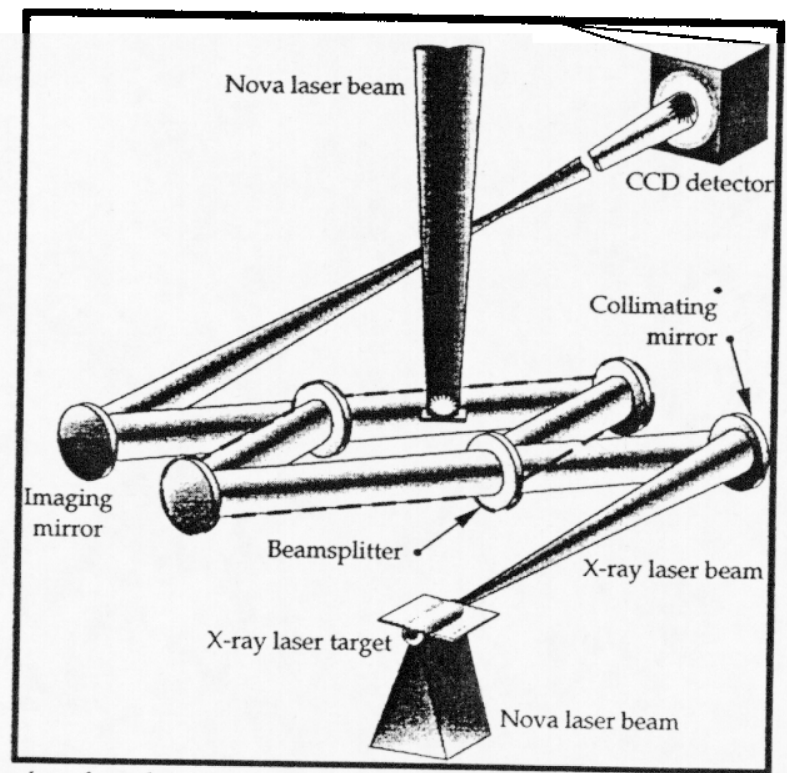

Figure 7. Experimental setup showing the components for plasma probing using a soft $x$

The experimental setup used to probe plasmas is shown schematically in Figure 7. The system consists of a collimated $x$-ray laser source, an imaging mirror and an interferometer. For our 
experiments we chose to employ a skewed Mach-Zehnder interferometer consisting of 2 flat multilayer mirrors and 2 multilayer beamsplitters. Each multilayer mirror consisted of a superpolished (<1 $\AA$ rms roughness) fused silica blank coated with 30 layer pairs of $55.9 \AA$ of Si and $23.9 \AA$ of Mo. The mirrors were measured to have a peak reflectivity of $60 \pm 5 \%$ at $155 \AA$. The beamsplitters used in the interferometer are the most critical element of the system. Soft $x$-ray beamsplitters with small apertures have been previously used in $x$-ray laser cavities ${ }^{19}$ but comparatively large open areas were necessary for our application. The active region of the beamsplitters used in the interferometer was $1.2 \mathrm{~cm} \mathrm{x} 1.2 \mathrm{~cm}$ and consisted of $1000 \mathrm{~A}$ of silicon nitride overcoated with 8 to 12 layer pairs of $\mathrm{Mo} / \mathrm{Si}$. The beamsplitters were fabricated from polished silicon wafers overcoated with $1000 \AA$ of silicon nitride. The silicon substrate thickness was varied from $0.4-0.8 \mathrm{~mm}$ with the best results being achieved with the thicker samples. The coated wafers were annealed to achieve maximum tension in the silicon nitride. Anisotropic silicon etching techniques were used to remove the silicon substrate from a $1.2 \mathrm{~cm} \times 1.2 \mathrm{~cm}$ area. The flatness of the beamsplitters was subsequently measured with an optical interferometer. Over the clear aperture the flatness was typically better than $5000 \AA$ for high quality silicon substrates but could be significantly worse (10000 A) for conventional thin $(0.4 \mathrm{~mm})$ silicon wafers. The figure quality was also extremely sensitive to the tension of the silicon nitride membrane. The best results were obtained with high stress membranes $(-200 \mathrm{MPa})$ which had a manufacturing yield of approximately $30 \%$. The measured reflectivity and transmission for these bearnsplitters at $155 \AA$ was $20 \%$ and $15 \%$ respectively. The overall throughput of each arm, accounting for the mirror and beamsplitter (one transmission $\&$ one reflection), was $\sim 0.018$.

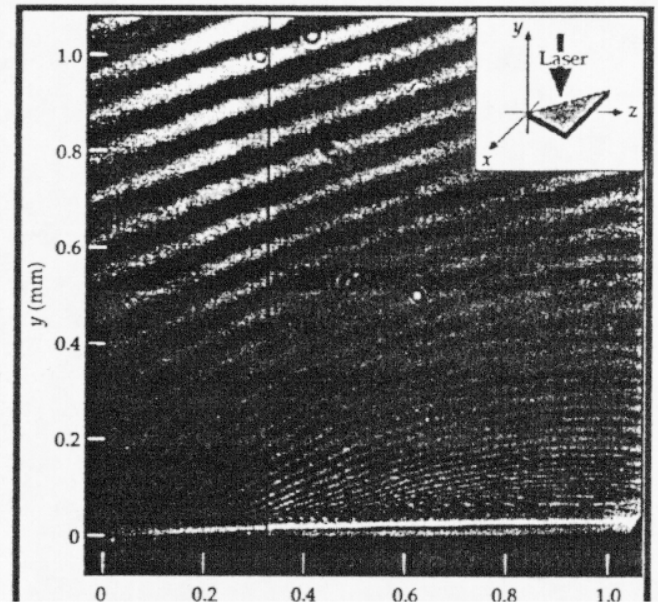

Figure 8. Interferogram of $\mathrm{CH}$ target irradiated at $2.7 \times 10^{13} \mathrm{~W} / \mathrm{cm}^{2}$. The inset shows the : geometry.

Again for these experiments a yttrium x-ray laser operating at $155 \AA$ was used as the probe source. The short pulse and high brightness of the $x$-ray laser allowed us to obtain an interferogram in a single 200 ps exposure thereby reducing the effects of vibrations. A spherical multilayer mirror placed $50 \mathrm{~cm}$ from the $\mathrm{x}$-ray laser was used to collimate the beam and inject it into the interferometer. The transverse coherence length after beam collimation was calculated to be $L_{s} \approx 50-100 \mu \mathrm{m}$ and the longitudinal coherence length is measured to be $L \approx 150 \mu \mathrm{m}$. The limited transverse and longitudinal coherence constrains us to match the two paths of the interferometer to maximize fringe visibility. The interferometer was pre-aligned on an optical bench using a $100 \mu \mathrm{m}$ optical fiber and a white light source. Observation of white light fringes was used to match the optical path lengths to better than $2 \mu \mathrm{m}$. The plasma to be probed was imaged onto a $C C D$ with a $100 \mathrm{~cm}$ radius of curvature multilayer mirror with an effective $f / \#=25$. A filter consisting of $1000 \AA$ of $\mathrm{Al}$ and $2000 \AA$ of lexan in front of the CCD eliminated optical light. To reduce background self-emission a series of 3 multilayer mirrors were used to narrow the bandpass of $4 \AA$, which is significantly broader than the $10 \mathrm{~m} \AA$ spectral width of the $x$-ray laser source. The image magnification was 19 giving a pixel limited resolution of $\sim 1.3 \mu \mathrm{m}$.

In Figure 8 we show the interferogram of a plasma produced by irradiating a silicon wafer overcoated with $10 \mu \mathrm{m}$ of $\mathrm{CH}$. The target was in the shape of a triangle to allow a range of plasma lengths to be probed simultaneously. The silicon substrate was polished to $\sim 7 \AA$ rms roughness 
to produce a clean flat surface. The $\mathrm{CH}$ side was irradiated with a beam smoothed with random phase plates and segmented with wedges to produce a flat-top intensity distribution over a $0.7 \mathrm{~mm}$ diameter spot ${ }^{20}$. A $1 \mathrm{~ns}$ square laser pulse with a wavelength of $0.53 \mu \mathrm{m}$ produced an intensity on target of $2.7 \times 10^{13} \mathrm{~W} / \mathrm{cm}^{2}$. The target was backlit edge-on by the $\mathrm{x}$-ray laser beam $1.1 \mathrm{~ns}$ after the start of the laser pulse. The image shows excellent fringe visibility and very little self emission from the plasma. This interferogram was analyzed and compared to simulations in a recent paper by Da Silva et al.2I.

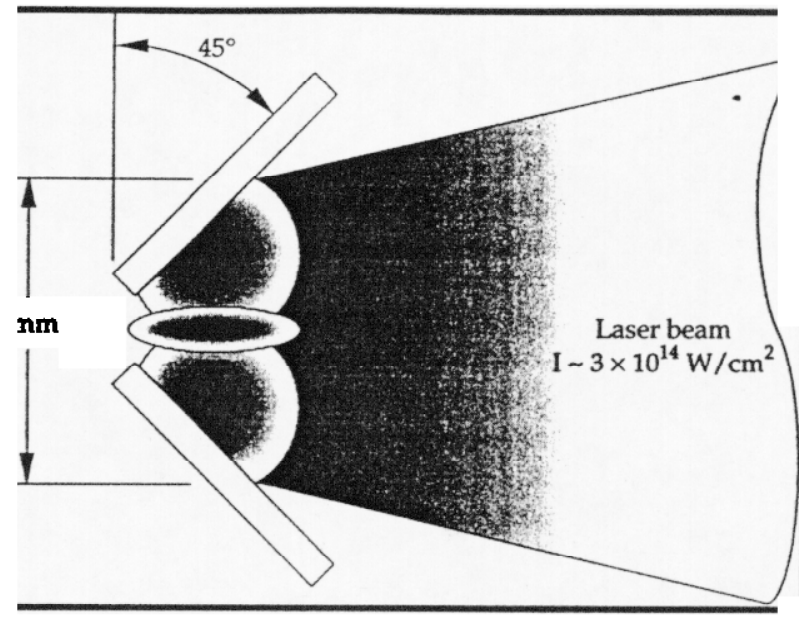

igure 9. Target geometry for studying colliding plasmas.

More recently we have used this interferometer to probe colliding plasmas which have relevance in ICF hohlraum experiments. The target consisted of two pieces of polished silicon $3 \mathrm{~mm}$ by $2 \mathrm{~mm}$ that were coated with $2 \mu \mathrm{m}$ of gold and positioned as shown in Figure 9. The target was irradiated at an intensity of $2 \times 10^{14} \mathrm{~W} / \mathrm{cm}^{2}$ ( $\lambda_{\text {laser }}=0.53 \mu \mathrm{m}, 1 \mathrm{~ns}$ square). The focal spot was $2 \mathrm{~mm}$ high and $0.5 \mathrm{~mm}$ wide and was produced by combining cylinder lens and random phase plates. The interferogram shown in Figure 10 was obtained at a time $1.0 \mathrm{~ns}$ after the start of the drive. There is clear evidence of interpenetrating plasmas. Figure $10 \mathrm{~b}$ shows the measured electron density profile along the line $A-A^{\prime}$ in Figure 10a. The region of plasma stagnation and interpenetration is $\sim 100 \mu \mathrm{m}$ which is larger then predicted by simple fluid codes which neglect interpenetration. For further details of these experiments refer to Wan et al. in these proceedings. This experimental configuration will allow us to vary the plasma temperature in future experiments to study the effects of plasma collisionality on the dynamics of colliding plasmas.
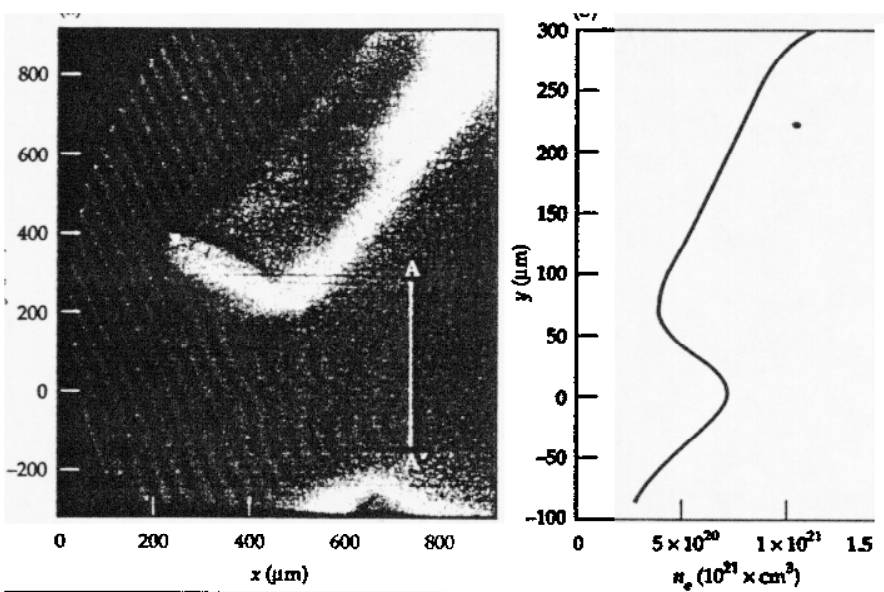

Figure 10. (a)

terferogram of colliding Au plasma.

(b) Electron density calculated ; ing line A-A:

\section{$V$. Conclusion}

In summary, the high brightness and short wavelength of $x$-ray lasers make them ideally suited for studying long scalelength and high density plasmas. The adverse effects of probe absorption and 
refraction can be significantly reduced by operating in the xuv. Using a yttrium $x$-ray laser we have been able to image thin irradiated foils with $\mu \mathrm{m}$ resolution and have demonstrated an accurate technique for quantifying the effects of beam imprinting on drive uniformity. By pushing the manufacturing of multilayer beamsplitters we have successfully developed soft $x$-ray interferometry and used it to probe a variety of laser produced plasmas. In the near future this technique will be used to diagnose the large and high density plasmas produced in ICF hohlraum targets.

Acknowledgements: We would like to thank the Nova Experiments Group for their assistance in these experiments. This work was performed under the auspices of the U.S. Department of Energy by the Lawrence Livermore National Laboratory under contract No. W-7405-ENG-48.

\section{References}

1. H. Daido, R. Kodama, K. Murai, G. Yuan, M. Takagi, and Y. Kato, Opt. Lett. 20, 61-63 (1995), L. B. Da Silva, R. A. London, B. J. MacGowan, S. Mrowka, D. L. Matthews, and R. S. Craxton, Optics Letters 19, 1532-1534 (1994), J. Nilsen, B. J. MacGowan, L. B. Da Silva, and J. C. Moreno, Phys. Rev. A 48 , 4682-4685 (1993), E. E. Fill, Y. L. Li, G. Preztler, D. Schlogl, J. Steingruber, and J. Nilsen, Physica Scripta 52, 158-161 (1995), T. Hara, K. Ando, and Y. Aoyagi, AIP Conference Proceedings 332, 181-185 (1995).

2. B. J. MacGowan, L. B. Da Silva, D. J. Fields, C. J. Keane, J. A. Koch, R. A. London, D. L. Matthews, S. Maxon, S. Mrowka, A. L. Osterheld, J. H. Scofield, G. Shimkaveg, J. E. Trebes, and R. S. Walling, Phys. Fluids 4, 2326-2337 (1992).

3. A. Carillon, H. Z. Chen, P. Dhez, L. Dwivedi, J. Jacoby, P. Jaegle, G. Jamelot, J. Zhang, M. H. Key, A. Kidd, A. Klisnick, R. Kodama, J. Krishnan, C. L. S. Lewis, D. Neely, P. Norreys, D. O'Neill, G. J. Pert, S. A. Ramsden, J. P. Raucourt, G. J. Tallents, and J. Uhomoibhi, Phys. Rev. Lett. 68, 2917-2920 (1992).

4. L. B. Da Silva, B. J. MacGowan, S. Mrowka, J. A. Koch, R. A. London, D. L. Matthews, and J. H. Underwood, Optics Lett. 18, 1174-1176 (1993).

5. J. J. Rocca, V. Shlyaptsev, F. G. Tomasel, O. D. Cortazar, D. Hartshorn, and J. L. A. Chilla, Phys. Rev. Lett. $75,1236-1236$ (1995).

6. J. J. Rocca, V. Shlyaptsev, F. G. Tomasel, O. D. Cortazar, D. Hartshorn, and J. L. A. Chilla, Phys. Rev. Lett. 73, 2192-2195 (1994).

7. L. B. Da Silva, J. E. Trebes, R. Balhorn, S. Mrowka, E. Anderson, D. T. Attwood, T. W. Barbee, J. Brase, M. Corzett, J. Gray, J. A. Koch, C. Lee, D. Kern, R. A. London, B. J. MacGowan, D. L. Matthews, and G. Stone, Science 258, 269-271 (1992).

8. C. W. Allen, Astrophysical Quantities., (Oxford University Press, New York, 1963).

9. J. Koch, B. J. MacGowan, L. B. D. Silva, D. L. Matthews, J. H. Underwood, P. J. Batson, and S. Mrowka, Phys. Rev. Lett. 68, 3291 (1992).

10. L. B. Da Silva, B. Cauble, G. Freiders, J. A. Koch, B. J. MacGowan, D. L. Matthews, S. Mrowka, D. B. Ress, J. E. Trebes, and T. L. Weiland, Proc. SPIE 2012, 158 (1994).

11. R. Cauble, L. B. Da Silva, J. T.W. Barbee, P. Celliers, J. C. Moreno, and A. S. Wan, Phys. Rev. Lett. 74, 3816-3819 (1995).

12. D. H. Kalantar, M. H. Key, L. B. Da Silva, S. G. Glendinning, J. P. Knauer, B. A. Remington, F. Weber, and S. V. Weber, Phys. Rev. Lett. 76, 3574 (1996).

13. M. H. Key, T. W. B. Jr., L. B. Da Silva, S. G. Glendinning, D. H. Kalantar, S. J. Rose, and S. V. Weber, J. Quant. Spectrosc. Radiat. Transfer 54, 221-226 (1995).

14. D. T. Attwood, D. W. Sweeney, J. M. Auerbach, and P. H. Y. Lee, Phys. Rev. Lett. 40, $184-186$ (1978).

15. G. Charatis, G. E. Busch, C. L. Shepard, P. M. Campbell, and M. D. Rosen, Joumal De Physique C6, 8998 (1986).

16. M. K. Prasad, K. G. Estabrook, J. A. Harte, R. S. Craxton, R. A. Bosch, G. E. Busch, and J. S. Kollin, Phys. Fluids B 4, 1569-1575 (1992).

17. P. E. Young, Phys. Fluids B 3, 2331-2336 (1991).

18. S. Wilks, P. E. Young, J. Hammer, M. Tabak, and W. L. Kruer, Phys. Rev. Lett. 73, 2994-2997 (1994).

19. A. M. Hawryluk, N. M. Ceglio, D. G. Stearns, K. Danzmann, M. Kühne, P. Müller, and B. Wende, Proc. SPIE 688, 81-90 (1987).

20. S. G. Glendinning, S. V. Wever, P. Bell, L. B. Da Silva, S. N. Dixit, M. A. Henesian, D. R. Kania, J. D. Kilkenny, H. T. Powell, R. J. Wallace, P. J. Wegner, J. P. Knauer, and C. P. Verdon, Phys. Rev. Lett. 69 , 1201-1204 (1992).

21. L. B. Da Silva, J. T.W. Barbee, R. Cauble, P. Celliers, D. Ciarlo, S. Libby, R. A. London, D. L. Matthews, S. Mrowka, J. C. Moreno, D. Ress, J. E. Trebes, A. S. Wan, and F. Weber, Phys. Rev. Lelt. 74, $3991-3994$ (1995). 


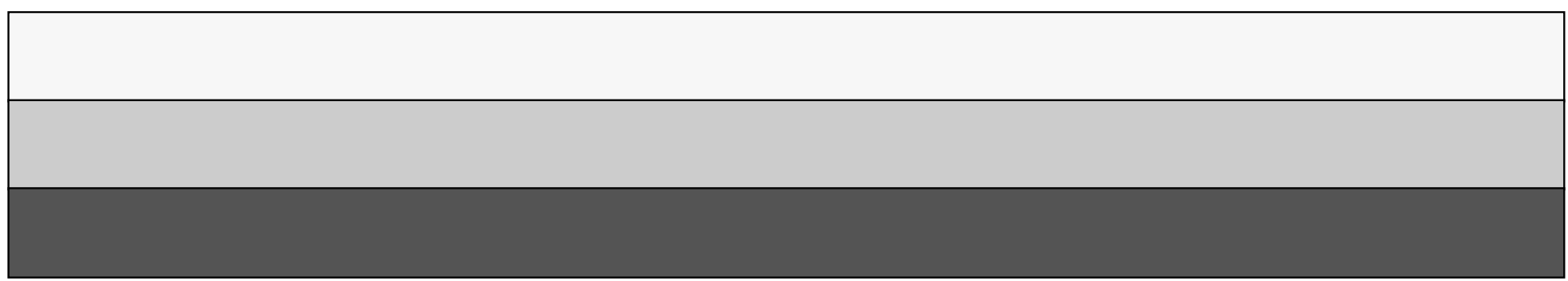

